\title{
THE COMPARATIVE METHOD: SIMPLICITY + POWER = RESULTS
}

\author{
EL MÉTODO COMPARATIVO: \\ SIMPLICIDAD + PODER EXPLICATIVO = RESULTADOS
}

\author{
BRIAN D. JOSEPH \\ The Ohio State University \\ bjoseph@ling.ohio-state.edu \\ ORCID: 0000-0001-7803-2772
}

DOI: $10.1387 /$ veleia.16817

\begin{abstract}
Since its introduction to the methodological tools available to historical linguists, the Comparative Method (CM) has proven to be one of the most powerful and enduring methods used, despite its apparent simplicity. In this paper, the bases for the CM are explored and, by way of demonstrating its utility and power, illustrative examples are provided of its application at all levels of linguistic analysis and of its extension even into cultural spheres.

Keywords: Comparative Method; Indo-European; reconstruction; comparative grammar; comparative law.

Resumen: Desde su introducción como herramienta metodológica disponible para la Lingüística histórica, el Método Comparativo ha demostrado ser uno de los métodos usados más potentes y duraderos, a pesar de su aparente simplicidad. En este artículo, se exploran las bases para el Método Comparativo y, con el fin de demostrar su utilidad y poder explicativo, se proporcionan ejemplos ilustrativos de su aplicación en todos los niveles del análisis lingüístico y de su extensión, incluso, hacia ámbitos culturales.

Palabras clave: Método Comparativo, indoeuropeo, reconstrucción, gramática comparada, ley comparada.
\end{abstract}

Recibido: 22-3-2016

Informado: 6-6-2016

Definitivo: 10-6-2016

\section{InTRODUCTION}

Franz Bopp's work on Indo-European grammar, as embodied especially in his 1816 work Über das Konjugationssystem der sanscrit Sprache in Vergleichung mit jenem der griechischen, lateinischen, persischen und germanischen Sprachen, is rightly regarded as the first application of the Comparative Method in linguistics ${ }^{1}$. Others before him employed comparison; for instance, Sir William Jones in

1 This method is referred to also sometimes as the "historical-comparative method"; see, e.g., Fowler 1957, though I prefer (and thus use here throughout) simply the term "Comparative Method". Fowler notes that Friedrich von Schlegel seems to have coined the term "comparative method", as it is used first in von Schlegel 1808. 
1786, in drawing attention to similarities of structure holding among Sanskrit, Greek, Latin, Gothic, and Celtic, was employing comparison, to be sure, but only in a most general way, doing so mainly to posit a common parentage for these languages but not really going further than that and not working out details of the nature of their parent language, the proto-language from which they originated. And, more generally, comparison of languages can be undertaken for a variety of purposes, as discussed below. Bopp, by contrast, was the first to systematically draw comparisons between elements in what were believed to be related languages for the purposes of reconstructing a common ancestor. It is thus possible, and indeed necessary, to distinguish between $a$ comparative method, with lower case used to indicate that it is indeed a common noun phrase, and the Comparative Method, capitalized and definitized so as to point to its special place in the methodology of linguistics.

In this essay, by way of commemorating Bopp and his important work of exactly two hundred years ago, I draw together threads of discussion in previous works of mine concerning the difference between comparative methodology in linguistics in general and the Comparative Method as a specific instantiation within historical linguistics of such an approach ${ }^{2}$. Moreover, I aim to demonstrate what it is about the Comparative Method that led historical linguist and Indo-Europeanist par excellence Calvert Watkins, one of the greatest practitioners of the Comparative Method in the $20^{\text {th }}$ century and into the $21^{\text {st }}$ century, to refer to it (Watkins 1995,4 ) as "one of the most powerful theories of human language put forth so far and the theory that has stood the test of time the longest". I examine here its power, even in the face of what Watkins characterized as its simplicity, by showing the wide range of results that are possible with it.

\section{The Comparative Method Explained and Differentiated}

As a tool available to comparatists in their respective armamentaria, the Comparative Method (hereafter, simply "CM") is indeed a powerful tool, and in a certain sense elegant too, in terms of what it can accomplish. At the same time, though, it is conceptually rather simple. Watkins himself (ibid.) says that "[t]he Comparative Method is not very complicated" and then proceeds to describe it thus:

"Put simply, the comparatist has one fact and one hypothesis. The one fact is that certain languages show similarities which are so numerous and so precise that they cannot be attributed to chance, and which are such that they cannot be explained as borrowings from one language into another or as universal or quasi-universal features of many or all human languages. The comparatist's one hypothesis, then, is that these resemblances among certain languages must be the result of their development from a common original language".

That is, in this view, there are four - and only four - means through which languages can show similarities: chance, universality, borrowing (contact), or genetic/genealogical relationship ${ }^{3}$;

2 As should become clear herein, this article is an homage not only to Bopp and his methodology but also to some extent to Calvert Watkins, appropriately enough, as he was one of my mentors in graduate school and provided me with many a fascinating model of the application of the Comparative Method.
3 The term genetic, even if intended to be used in the sense of its Greek source, $\gamma \varepsilon v \varepsilon \tau \iota k o ́ \varsigma$ 'pertaining to origins', can now be confused with genetic in the biological sense, pertaining to DNA and the like; for that reason, some linguists have come to prefer the term genealogical for the former sense of genetic when talking about language origins. 
the $\mathrm{CM}$ allows one to reject the first three and thus to zero in on the last, in which languages are sprung from a common source. The explanations for similarities among languages that the CM rejects exemplify other ways in which comparison can be used in linguistics.

For instance, in the study of the effects of language contact, what is now generally known as "contact linguistics" (e.g., see Winford 2003 on this designation), a suggestion of contact-induced change in a language usually starts with a comparison of two (or more) languages that historically have at least a geographical connection between them or between groups of their speakers. But comparison is key, initially even to isolate features that are parallel across languages and which could conceivably be present in one as a result of contact with the other language, but ultimately to determine, ideally through a careful application of the $\mathrm{CM}$, whether or not the feature might be considered an inherited feature in the language in question. Thus comparison in a generalized sense, as well as in the specialized form of the CM, is an essential part of any discussion of language contact.

Further, with regard to universals of language, they are arrived at in part by comparison that is typologically inspired. In principle one can posit potential universals of language by recourse to data from a single language, inasmuch as the notion of "human language" in its broadest sense must be able to accommodate data from any language, even if that language is unique with regard to the feature(s) in question. However, the proof of the pudding, so to speak, as far as universals are concerned, can only come from how widespread a feature is cross-linguistically, and that requires comparative evidence, examining how many languages have a given feature or particular combination of features. But such an examination is not genealogically oriented, and in fact should not be, as a way of guarding against the possibility that said feature occurs in several related languages by virtue of their common parentage.

And, finally, even chance similarities between languages require comparison in order to come to light. The only way to identify relevant features whose origin can then be examined is by comparing, for instance, the lexical inventories of various languages to look for sound-alike words that happen to have similar meanings. The example that Watkins (ibid.) cites, of Nahuatl teo-tl 'sacred' and its chance partner, Greek $\theta \varepsilon$ ó$_{\varsigma} \varsigma$ 'god' (alternatively, Latin deu-s 'god'), could only be considered by someone who was familiar, quite possibly to very different degrees, with both languages and who made a comparison, drawing the possible connection in the vocabularies of each language involved.

That is, other methodologies employ comparison but not in the same sense as Watkins's comparatist, i.e. comparison in and of itself is not the CM. Comparison in connection with the study of linguistic contact, the study of linguistic universals, and the study of linguistic chance has very different goals from comparison in connection with testing a linguistic genealogy. The rigor and precision of the CM, with its goal of identifying comparable elements in genealogically related languages, are lacking in these other cases.

\section{What THe CM CAN Do}

Once it is seen how the CM can be differentiated from other types of comparison, it can be asked just what the $\mathrm{CM}$ can do. I turn first to a number of important side benefits that this methodology offers before considering the different kinds of reconstruction that are possible through it. 
First, when the CM "works", in the sense of offering systematic sets of comparable elements between and among various languages, it can be said to demonstrate and thus prove genealogical relatedness among those languages. What is crucial here is the notion of systematicity. Numbers alone can rule out chance, in that one may expect that a few similarities might hold between any two languages due to chance, but large numbers of similarities would hardly be expected to occur by chance alone. In the same way, similarities based on universal aspects such as onomatopoeia or sound symbolism might be expected to be focused on the lexicon only, and just on a subset of the lexicon at that. And borrowings generally show a greater degree of overt similarity than forms derived from common parentage show, as seen in the difference between the cognate forms English tooth and Latin dent- as opposed to English dental, a borrowing from Latin dentalis. An extreme case of this sort is seen in the comparison of English or Latin word-initial s- with Albanian gj-, as in Latin serpent- = Albanian gjarpër 'snake' or English salve = Albanian gjalp 'butter', to name just a few of the many forms that fit this correspondence, where the cognate elements have almost no distinctive features in common and yet match up in a thoroughly regular and systematic way. Indeed, when the comparable elements line up systematically, and cover wide swaths of the grammar and lexicon of the languages in question, something more than chance, borrowing, or universality has to be at issue, and that something more is parallel descent from a common source. Thus the comparisons made within the CM can lead to confirmation of common parentage, confirmation of genealogical relatedness.

Also, though, once relatedness is established, the CM allows, and in fact requires one to ask what the nature of that common parent was, and in particular, what form in the parent language could have given rise to the elements being compared. That is, the CM brings the comparatist to the interesting point of being able to reconstruct the earlier linguistic state that was the ancestor of those related languages.

Further, once an ancestral state for a set of related languages is posited, the comparatist is in the position of being able to learn something about language change. That is, reconstruction in part depends on what we know about language change, so that a plausible path can be posited from the reconstructed form to the attested forms that were the starting point for the comparative exercise. But it also provides information about language change to the extent that the reconstruction is believable. Reconstruction via the CM thereby also feeds our understanding of language change. And even in the absence of reconstruction, the CM can tell us indirectly about language change; as noted in Joseph 2001, if it is known that two languages are related and that a feature $\mathrm{X}$ in one matches, i.e. is to be compared with, a feature $\mathrm{Y}$ in the other, and if $\mathrm{X}$ and $\mathrm{Y}$ are not identical, the CM tells us that at least one change has taken place: either $\mathrm{X}$ was inherited as such and $\mathrm{Y}$ has changed, or vice-versa, or perhaps both have changed from an ancestral state that was not the same as either one. Reconstruction then offers a concrete solution to which of those possibilities makes the most sense, but comparison alone in such an instance points to the fact of there having been some change.

\section{Considering Reconstruction more DeEPLy}

Comparative reconstruction, based on the CM, therefore, has several side benefits that go beyond just simple reconstruction for its own sake. It is worth asking, therefore, just what "simple reconstruction" can entail, and in particular, what can be reconstructed using the CM. This is a fair question because so much of what is focused on in illustrating the CM in textbooks on historical linguis- 
tics is the $\mathrm{CM}$ as applied to sounds $s^{4}$. Moreover, the Neogrammarians, as the successors to Bopp and his study of Indo-European, are themselves known especially for the principle of regularity of sound change, which emerged from a consideration of the regular sound correspondences that formed the basis of the reconstruction of Proto-Indo-European. It is therefore easy to think that the CM is a method to be employed primarily for studying sound change and for reconstructing sounds 5 .

However, it can be noted in this regard that Bopp himself actually did more morphological and grammatical reconstruction in his 1816 work than phonological reconstruction per se. The title of his work makes this clear, as his focus is the "Konjugationssystem" of the various languages he examines. Thus, it is fair to ask whether reconstruction via the CM really is limited to, or best suited for, the reconstruction of sound systems. That is, one can wonder what the range of reconstructions is that the CM can lead to.

The obvious answer is that while yes, of course the CM allows for the reconstruction of sounds, sounds do not occur independently; rather they are embedded in words and morphemes. That is, sound correspondences - a focal point in the application of the CM because of a special characteristic that sound change shows, namely regularity, that is not found with change in other levels of grammar- emerge out of the comparison of words and morphemes. This basic fact means that one can add together the reconstructed sounds in a particular set of comparanda and use them to reconstruct a full form of individual words and morphemes, thereby giving concrete shape to the lexicon of the reconstructed proto-language. Nor is it the case that sounds occur atomistically; rather they are involved in patternings with other sounds so that reconstructed sounds fall in with other like reconstructed sounds and are opposed to other different reconstructed sounds and thereby form phonological systems. These abstract grammatical systems have featural similarities and featural contrasts; for Proto-Indo-European, contrasts can be reconstructed in point of articulation, by which, for instance, the labials (*p, etc.) are opposed to the dentals $\left({ }^{*}\right.$ t, etc.) and such "front" consonants are opposed to "back" consonants like the velars (*k, etc.), as well as in secondary articulation, as with the velars versus the labio-velars $\left({ }^{*} \mathrm{k}^{\mathrm{w}}\right.$, etc.).

In Joseph $(2004,49)$, I offer a listing of some of the successes of the CM that highlight its ability to offer insight into the proto-language at a variety of levels of analysis. I offer it again here, by way of honoring Bopp, but with embellishments and further examples from Indo-European in order to demonstrate once again what it allows us to do, and therefore to exemplify the power of the method that Watkins referred to.

In the reconstruction of morphemes, we can include not only the form of content morphemes such as verbal roots, for instance:

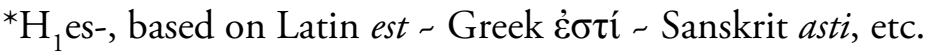

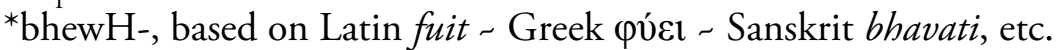

*bher-, based on Latin ferō - Greek $\varphi \varepsilon ́ \rho \omega$ - Sanskrit bharati, etc.

*wert-, based on Old English weorðan - Sanskrit vartate, etc.

*nem-, based on Greek vé $\mu \omega$ - Gothic niman, etc.

* $\mathrm{deH}_{3}{ }^{-}$, based on Latin $d \bar{o}-$ Greek $\delta i ́ \delta \omega \mu \mathrm{l}$ - Sanskrit dadāmi, etc.

4 Without wanting to provide a catalog of textbooks, I mention here only the one that I am associated with, Hock and Joseph 1996/2009, taking it as representative of the lot.
5 Note, for instance, the Cambridge University Press advertising blurb for Heine and Kuteva 2002, discussed in Joseph $(2004,48)$, in which it is said that "the comparative method is concerned with regularities in phonological change". 
inter alia, and nominals, for instance:

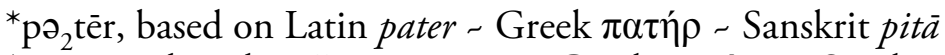

${ }^{*} \mathrm{p}_{2}$ term, based on Latin patrem - Greek $\pi \alpha \tau \varepsilon \dot{\varepsilon} \rho \alpha$ - Sanskrit pitaram

*swepnos, based on Greek vँ $\pi v o \varsigma$ - Sanskrit svapnas

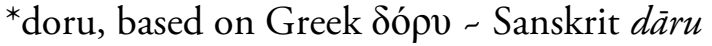

*medhu, based on English mead - Greek $\mu \varepsilon \dot{\theta} v$ - Sanskrit madhu

*ǵonu, based on Latin genu - Greek yóvv - Sanskrit jānu

inter alia, but also the specific meanings of these morphemes, i.e.:

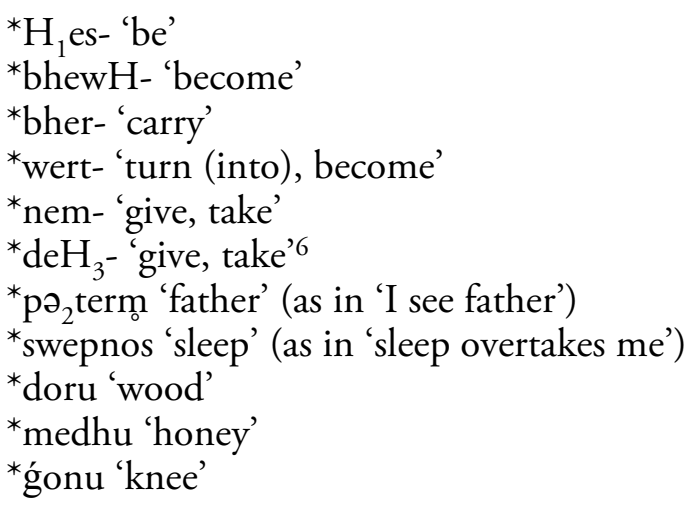

among numerous others ${ }^{7}$. In addition, grammatical forms can be reconstructed, such as *-mi and ${ }^{*}$-ti in the verbal system, ${ }^{*}$-m and ${ }^{*}$-s in the nominal system, and grammatical values can be assigned to them, so that they are true grammatical morphemes, pairings of form and meaning:

*-mi 'first person singular present' (as in $\delta \dot{\delta} \delta \omega-\mu \mathrm{l}-d a d \bar{a}-m i$ 'I give')

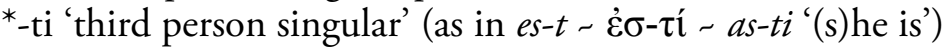

*-m 'accusative singular' (as in patr-em $-\pi \alpha \tau \varepsilon \dot{\varepsilon} \rho-\alpha$ )

*-s 'nominative singular' (as in vँ $\pi v 0-\varsigma \sim$ svapna-s)

Moreover, the *-u of ${ }^{*}$ doru/medhu/ǵonu can be segmented off and treated as a stem-formative, figuring in matters of nominal derivation ${ }^{8}$.

These grammatical morphemes, and others reconstructed in the same way, give a set of grammatical categories that are relevant for the proto-language. For Proto-Indo-European, based on congruences across the different languages of the family, grammatical categories such as person, number, present tense, past tense, perfective aspect, stativity, imperative mood, optative mood, nominative case, accusative case, can all be reconstructed, though there is considerable controversy over the details of reconstruction, both as to form and as to category.

Relevant too in the reconstructed grammar of the proto-language, based on comparative evidence across the different languages, are various morphological processes that serve both an inflectional and a derivational function. For instance, based on comparanda like $\delta i ́ \delta \omega-\mu 1 \sim d a d \bar{a}-m i$ and

6 See below on the semantics of these last two roots.

7 Any of the several compendia of Proto-Indo-European reconstructed roots and forms, e.g. Watkins 2000 , offer dramatic evidence of what the CM allows for in the way of reconstructed lexicon.
8 However, these nouns most likely are isolated forms, in that there are no obvious verbal roots from which they can be derived, even if the ${ }^{*}-\mathrm{u}$ is otherwise a derivational morpheme. 
other verbs like them, a process of reduplication as a way of forming present tense verbal stems can be identified, and reduplication with a different vowel can be posited as having been opera-

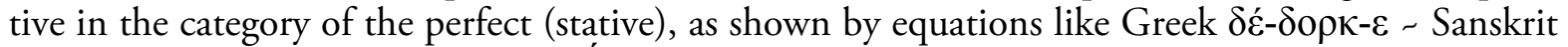
da-darś-a '(s)he has seen' (< ${ }^{*}$ de-dork-e). Similarly, vowel gradation (ablaut) can mark grammatical distinctions, as shown by the nominative forms with an original long vowel in the final sylla-

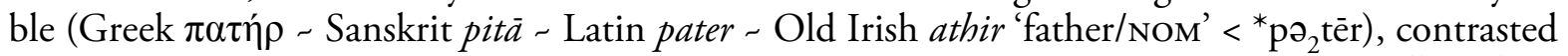
with the short vowel in the accusative forms cited above (Greek $\pi \alpha \tau \dot{\varepsilon} \rho-\alpha$, etc.) $)^{9}$, as well as derivational relationships, e.g. as shown by verbal forms with $-e$ - vocalism in the root versus derived nominals with $-o$ - vocalism, as in Latin tego 'I cover' - tog $\bar{a}$ 'covering', matching the process seen in Greek $\lambda \dot{\varepsilon} \gamma \omega$ 'I say' - $\lambda$ ó $\gamma$ os 'speech, word'.

Staying with the morphological component, it is possible to use alternations in the various languages as the basis for the reconstruction of morphophonemic rules that were operative in the proto-language. This step is important, since it shows that the proto-language can be treated like any synchronic linguistic system, that is to say, it comes not only with a lexicon and with morphemes that have phonological shapes that can be recovered, but the relationships between and among these phonological shapes can also be seen to have been mediated by synchronic rules. A case in point comes from a consideration of the irregular second person singular forms of the present tense of 'be' ('you are') in Sanskrit and Greek. The Sanskrit form is asi, with a single -s- where one would expect instead assi, based on the root form as- seen in the first person and third person singular forms, asmi and asti respectively, and the ending -si seen in other second person singular forms, e.g. bharasi 'you carry'. The same holds for Greek, where eĩ occurs, from earlier *ehi from earlier *esi, also with a single $^{*}$-s-, just as in the Sanskrit form, where again a double -ss- would be expected ${ }^{10}$. The matching irregularity in Greek and Sanskrit gives a basis therefore for reconstructing ${ }^{*} \mathrm{H}_{1}$ esi for the Proto-Indo-European form for 'you are'; however, comparing that with the root ${ }^{*} \mathrm{H}_{1}$ es- and the second person singular ending *-si, one can posit a morphophonemic rule of $s s==>s$ that was operative in taking the underlying (morphologically based) form $/{ }^{*} \mathrm{H}_{1}$ es-si/ and converting it to the preform for the Greek and Sanskrit, $\left[{ }^{*} \mathrm{H}_{1}\right.$ esi $]$.

And, to give a taste of CM in syntax, one can point to the anomaly of neuter plural nouns gov-

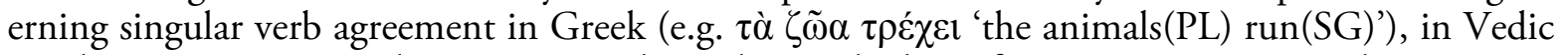
Sanskrit, in Avestan, and in Hittite, and use that as the basis for positing a Proto-Indo-European rule of verb agreement with that peculiarity.

As far as the reconstruction of semantics is concerned, the meanings given above show what can be done in that linguistic level. But beyond the concrete semantic matchings seen in those word and morpheme comparisons, reconstructible metaphorical meanings can also be discerned. For instance, the equation of Greek Zeṽ $\pi \alpha ́ \tau \varepsilon \rho$ 'O father Zeus (vocative) = Iüpiter 'Jupiter' (NominaTIVE but based on a vocative — note that the genitive is Iovis, without -piter), along with the clearly cognate Sanskrit dyaus pitā, points to a pairing *dyeus pə. 2 ter- 'Father Sky' in Proto-Indo-European with a metaphorical sense of 'father', not a biological sense or one pertaining to the (human) nuclear family.

9 The - - - in Latin genu as opposed to the -o- in Greek yóvv (and Sanskrit jānu) suggests an original intra-paradigmatic alternation between $-e$ - vocalism and $-o$ - vocalism in the root (leveled out in different directions in the different languages).

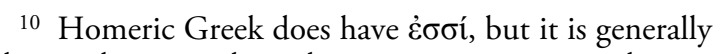
taken to be an analogical innovation, not an archaism, because it shows regularization of the irregular $\varepsilon \tilde{i}$. 
Moreover, in some instances, semantic differences between cognate forms can be resolved in such a way as to shed light on how certain actions must have been viewed in the proto-language. The example of 'give' and 'take', noted above for the reconstructions *nem- and ${ }^{*} \mathrm{deH}_{3}$-, is a case in point. Here there are reconstructed items in which the comparanda upon which the reconstructions are based show opposite semantics: Greek vé $\mu \omega$ has a 'give' sense while Germanic, e.g. Gothic, niman means 'take', and for * $\mathrm{deH}_{3}$,, while Greek and Sanskrit have the meaning 'give', the Hittite cognate, $d a$-, means 'take'. Such opposite semantics involving verbs pertaining to a transaction have long been noted, and are discussed in Joseph 2000 regarding the connection between Latin habere 'to have' and Germanic, e.g. Gothic, giban and its German cognate geben, in the context of the existential use of the verb in German, es gibt 'there is'. Drawing on work by Watkins and others, it is argued there that the opposite semantics can be reconciled by viewing the verbs as referring to the global transaction in which there is a giver and a taker, and seeing each verb as having lexicalized a different perspective on the transaction. In this way, therefore, the Proto-Indo-European verb can be reconstructed not as having one or both meanings really but rather a more general reference to the overall transaction.

The language of different literary genres can be reconstructed, as with the observation by Adal-

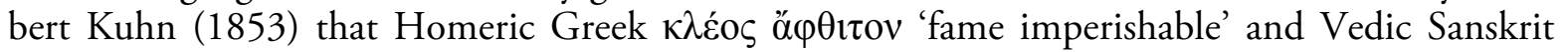
sravah ... aksitam 'idem' constitute the basis for a Proto-Indo-European poetic formula. And since then, numerous instances of Indo-European formulaic phraseology, often rich with metaphor in its own right, have been identified, a good many by Calvert Watkins, as detailed especially in Watkins (1995).

And, culturally loaded vocabulary can be reconstructed, involving not just names of deities but also specifiers of the deities that match up well that summon up images of just how the Indo-Eu-

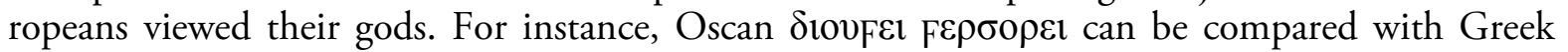

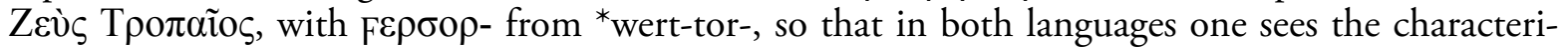
zation of the chief god of the pantheon as "the Turner" (i.e., turning enemies away, thus "granting victory"). Here the specific verb for 'turn' is different (*wert- for Oscan, *trep- (> $\tau \rho \varepsilon \pi-)$ for Greek), so that the focal point of comparison and thus of reconstruction is the semantics, and thus the particular image for the god in question.

Finally, as Watkins 1970 has demonstrated, to take another area in which linguistic reconstruction and cultural reconstruction can go hand in hand, both Proto-Indo-European legal practice and legal diction can be reconstructed. A telling example is Watkins's discussion of the treatment, in Roman, Greek, and Hittite law, of offenses committed by someone who is not a legal person, i.e. an animal, a child, or a slave. In such cases, all three legal traditions specify the same options of either restitution or handing over the offender to the aggrieved party and use parallel diction - the verb sarcire 'make amends for' in Latin and sark- 'make restitution for' in Hittite, and a form of the root ${ }^{*} \mathrm{deH}_{3}$ - for 'hand over' in both Greek and Latin. These parallelisms allow for the reconstruction of an aspect of the law code of the Proto-Indo-Europeans and the specific language used in the statement of the legal remedies for that particular issue. And even in the absence of specific linguistic parallelism, thematic parallelism can be suggestive of a reconstructible prototype; Joseph $(2011,2016)$ has argued that parallels between Albanian bee-related law as expressed in the Kanun of Lek Dukagjin (Fox 1989) and Old Irish bee-law as expressed in the early Irish bee-treatise Bechbretha (Charles-Edwards and Kelly 1983) allow for a glimpse into the legal concerns of beekeeping for the Proto-Indo-Europeans, such as establishing ownership of swarms of bees that have left the hive and settled elsewhere. 


\section{Conclusion}

By way of conclusion, it must be emphasized that the CM, for all its power, cannot provide answers to all issues the comparatist faces. For instance, the formal matching of a stem-forming verbal affix -sc- in Latin, $-\sigma \kappa$ - in Greek, $-s^{k} k$ - in Hittite, - (c) $c h$ - in Sanskrit, and - $h$ - in Albanian ${ }^{11}$, allowing for the reconstruction of a Proto-Indo-European verbal stem-formative ${ }^{*}$-sk-, is not matched by congruent semantics in the various languages. In Latin and Greek, the suffix has an inchoative or imperfective value, in Hittite, it marks iterativity, in Sanskrit, it is one of many present-tense formatives, while in Albanian, it marks nonactive (mediopassive) voice, but only in the present tense. There is thus something presential about the suffix, but the range of meanings offers a serious challenge for the reconstruction of the function of this suffix. Still, adherents who champion the CM can take heart in knowing that without the formal comparison that the CM presents for this suffix, the functional reconstructive challenge it poses would not even be an issue. Thus, even when it fails, so to speak, the CM has the power to guide and inform our reconstructions.

\section{REFERENCES}

Charles-Edwards, Th., and F. Kelly, 1983, Bechbretha (Early Irish Law Series Volume 1), Dublin: Dublin Institute for Advanced Studies.

Fowler, M., 1957, «The Historical-Comparative Method», The Classical Journal 52.6, 259-264.

Fox, L., 1989, Kanuni I Lekë Dukagjinit. The Code of Lek Dukagjinit. Albanian text collected and arranged by Shtjefën Gjeçov. Translated, with an Introduction, by Leonard Fox, New York: Gjonlekaj Publishing Co.

Heine, B., and T. Kuteva, 2002, World Lexicon of Grammaticalization. Cambridge: Cambridge University Press.

Hock, H. H., and B. D. Joseph, 1996/2009, Language Change, Language History, and Language Relationship. An Introduction to Historical Linguistics, Berlin: Mouton de Gruyter ( $1^{\text {st }}$ ed. 1996; $2^{\text {nd }}$ ed. 2009).

JosePH, B. D., 2000, "What gives with es gibt? Typological and comparative perspectives on existentials in German, in Germanic, and in Indo-European", Studies in Memory of Edgar C. Polomé. American Journal of Germanic Linguistics and Literatures 12.2, 187-200.

—, 2001, «Historical Linguistics», in M. Aronoff \& J. Rees-Miller (eds.), Handbook of Linguistics, Oxford: Blackwell Publishers, 105-129.

—, 2004, "Rescuing Traditional (Historical) Linguistics from Grammaticalization "Theory”», O. Fischer, M. Norde, \& H. Perridon (eds.), Up and Down the Cline - The Nature of Grammaticalization, Amsterdam: John Benjamins, 44-71.

—, 2011, "Comparative Perspectives on Early Irish Bee Law», Paper presented at annual meeting of Celtic Studies Association of North America, The Ohio State University, 20 May 2011.

—, 2016, "Comparative Perspectives on Bee Law in Indo-European». Paper presented at 35th meeting of the East Coast Indo-European Conference (ECIEC 35), University of Georgia, 6 June 2016.

Kunn, A., 1853, "Ueber die durch nasale erweiterte verbalstämme», Zeitschrift fur Vergleichende Sprachforschung 2, 455-471.

von Schlegel, F., 1808, Über die Sprache und die Weisheit der Indier, Heidelberg: Mohr und Zimmer (reprinted in a new edition, 1977, by John Benjamins, Amsterdam).

11 For the phonology, cf. Greek бкía - Sanskrit chāya - Albanian hijë 'shade, shadow'. 
Watkins, C. W., 1970, «Studies in Indo-European legal language, institutions, and mythology», in G. Cardona, H. Hoenigswald and A. Senn (eds.), Indo-European and Indo-Europeans, Philadelphia: University of Pennsylvania Press, 321-354.

-, 1995, How to Kill a Dragon. Aspects of Indo-European Poetics, Oxford: Oxford University Press. —, 2000, The American Heritage Dictionary of Indo-European Roots, Boston: Houghton Mifflin.

Winford, D., 2003, Introduction to Contact Linguistics, Oxford: Wiley-Blackwell. 